\title{
Prospective Observational Study for Perioperative Volume REPLACEMENT With 6\% HES 130/0,42, 4\% GELATIN AND 6\% HES 200/0,5 in CARDiac SuRgERY
} \author{
A. Koester ${ }^{1}$, N. Rahe-Meyer ${ }^{2}$

\begin{abstract}
${ }^{1}$ Department of Anaesthesiology, University of Düsseldorf, Germany, ${ }^{2}$ Department of Anaesthesiology, Hannover Medical School, Germany, ${ }^{3}$ Department of Surgery, University of Düsseldorf, Germany
\end{abstract}

M. Winterhalter ${ }^{1}$, P. Malinski², O. Danzeisen ${ }^{1}$, S. Sixt ${ }^{1}$, E. Monaca ${ }^{1}$, T. Jüttner ${ }^{1}$, M. Peiper ${ }^{3}$, P. Kienbaum ${ }^{1}$,

\begin{abstract}
Background: The constantly growing amount of different kinds of colloid fluids necessitates comparative investigations with regards to the safety and effectivity in clinical use of these preparations. Hence we compared three colloid fluids in an observational study. The objective was the exploration of the influence of these three colloids on blood coagulation, hemodynamics and renal function of the cardiac surgical patient.
\end{abstract}

Methods: We included 90 patients undergoing an elective open-heart surgery with the use of the heart-lung machine and observed them consecutively. Group 1 [gelatin 4\% $(\mathrm{n}=30)$ ], Group 2 [HES 200/0,5 $(\mathrm{n}=$ 30)] and Group 3 [HES 130/0,42 (n = 30)]. We measured the perioperative volume replacement, the administration of blood- and coagulation-products, the application of catecholamines, the renal function, blood gas and the platelet aggregation using multiplate electrode analyzer (Multiplate ${ }^{\circledR}$, Dynabyte medical, Munich, Germany).

Results: The gelatin-group needed significantly more norepinephrine than the HES 130/0.42 group. The responsible surgeon considered the blood coagulation in the HES 200/0.5 group most frequently as impaired. Furthermore we saw a significant decrease in platelet function in the HES 200/0.5 group when performing the multiplate ${ }^{\circledR}$-analysis (ADP-and COLtest). HES $130 / 0.4$ as well as gelatin $4 \%$ showed no significant change in platelet function. The gelatingroup and the HES 200/0.5 needed significantly more aprotinine than the HES 130/0.4 group. We saw no significant difference with regards to administration of blood and coagulation products between the three groups. The urinary excretion during the intervention was significantly higher in the HES 200/0.5 group and in the gelatin group than in the HES 130/0.4 group.

Conclusions: Our results confirm the lower stabilizing effect of gelatin on circulation during fluid resuscitation. The blood coagulation was mostly impaired due to HES 200/0.5 confirmed by the multiplate ${ }^{\circledR}$-analysis as well as by different clinical findings.

\section{INTRODUCTION}

Cardiac surgery is associated with extended blood loss resulting in hypovolemia, circulatory dysregulation and deficient tissue perfusion. Therefore an urgent adequate intravascular volume therapy is essential for the management of these patients and in avoiding organ dysfunction. The advantage of colloids over crystalloids in effective volume replacement and improving haemodynamics has been confirmed and reviewed in several studies [1-3]. Hence colloids are widely used in fluid resuscitation and especially hydroxyethylstarch (HES) has become an established approach to correct hypovolemia under a variety of conditions [4].

The origin of hydroxyethylstarch is waxy maize amylopectin, a highly branched polysaccharide similar to glycogen. The structure of HES is determined by mainly 1-4 linkages of polymerized glucose and 1-6 branching linkages. Thus the degradation of HES by the serum _-amylase is elongated and its elimination from the blood circulation delayed. It was shown that the molecular weight $(\mathrm{Mw})$ plays only a minor role in determining the pharmacological profile of HES solutions [5]. Rather the degree of molar substitution (MS) and the substitution ratio at C2/C6 seem to determine the pharmacological profile of each HES preparation [6].

Diverse HES-preparations are considered to alter blood coagulation and inducing platelet dysfunction to a certain extend. However, HES preparations represent a good compromise of sufficiently treating hypovolemia and an overall low rate of adverse drug reactions [7]. There is a wide range of HES preparations available and the last $3^{\text {rd }}$ generation of HES has been approved by the Food and Drug Administration (FDA) in 2008 [8]. The $3^{\text {rd }}$ generation of HES preparations has a Mw of $130 \mathrm{kD}$ and a MS <0,.supposed to alter coagulation to a lower extend than HES preparations with a higher $\mathrm{Mw}(200 \mathrm{kD})$ and a higher MS $(0.5)[8,9]$. However some authors saw no differences with regard to coagulation, bleeding and transfusion requirements when comparing different HES preparations $[10,11]$. 
In the present observational study we compared three colloids $(6 \%$ HES 130/0.42, 4\% gelatin, 6\% HES 200/0,5) in respective to coagulation, estimated blood loss, transfusion requirements, hemodynamics and renal function. Besides collecting and evaluating clinical data we used the multiple electrode analyzer (Multiplate $^{\circledR}$ ) for detecting platelet dysfunctions.

\section{Methods}

After the approval of the local ethics committee, we separated a collective of 90 patients in three equal groups each counting 30 patients. We included only patients who had to undergo an elective open-heart surgery with the use of the heart-lung machine in our observations. Further inclusion criteria were the minimum age of 18 years and no contraindications against the administration of colloids. The observation period started with the anesthetic induction and ended 24 hours after the open-heart surgery on the ICU. We collected diverse clinical data during this period and it was documented in a standardized sheet.

The first group received 6\% HES 130/0,42 (Venofundin ${ }^{\circledR}$, B. Braun), the second group $4 \%$ gelatin (Gelafundin ${ }^{\circledR}$, B. Braun) and the third group received 6\% HES 200/0,5 (Hemohes ${ }^{\circledR}$, B. Braun). Because we performed an observational study during clinical routine without a study setting there was no randomization and blinding of the 90 patients possible. In the range of our clinical routine we administered each patient $500 \mathrm{ml}$ of the respective colloid during the anesthetic induction. If necessary the respective patient received only the same colloid during the whole openheart surgery.

Preoperatively we documented the age, sex, bodyweight, height, the body mass index (BMI), the concomitant medication and concomitant diseases of each patient. We registered anamnestic coagulation disorders, the bleeding tendency in family history and classified each patient according to the ASA-score. Furthermore we calculated the Euroscore (http:// euroscore.org/calc.html.) for each patient, which describes the probability of mortality during cardiac surgery. Also the main diagnosis, the type of surgery being performed and different time intervals concerning the surgery and the hospitalization were captured.

We separated the observation period in phase 1 (from the beginning of the anesthetic induction till the end of surgery) and in phase 2 (from the end of surgery till 24 hours stay on the ICU). Perioperatively we documented the amount of crystalloids administrated, the administration of blood components (red blood cells, fresh frozen plasma, platelet concentrates) and the urinary excretion. Besides we registered the use and given amount of aprotinine, heparine, protamine and catecholamine's (norepinephrine, dobutamine). All data concerning the monitoring of the cardiovascular system as well as diverse laboratory parameters and blood gas values measured routinely during open-heart surgery were captured for each patient. In addition the responsible surgeon evaluated and graded the blood coagulation during the surgery.

For assessing platelet function we used the multiplate electrode analyzer (Multiplate ${ }^{\circledR}$, Dynabyte med- ical, Munich, Germany). The blood for the multiplate $^{\circledR}$ analysis was drawn from each patient before and after the administration of the respective colloid during the anesthetic induction. The infused amount of each colloid was exactly $500 \mathrm{ml}$. The analysis was performed immediately in a near-patient setting. The multiplate electrode analyzer measures electrical impedance between electrodes immersed in whole blood. Blood is stirred using an electromagnetic stirrer by 800 rpm. The attachment of platelet aggregates on the electrodes increase the impedance between them. The impedance change is transformed to arbitrary aggregation units (AU) by the system software and plotted against time [12]. The multiplate ${ }^{\circledR}$ system allows the evaluation of platelet function after being activated by the agonists' adenosine diphosphate (ADP, $6.4 \mu \mathrm{M}$ ), collagen (COL, $3.2 \mu \mathrm{g} / \mathrm{ml}$ ) and thrombin-receptor-activated protein (TRAP, $32 \mu \mathrm{M}$ ). The three agonists used were added to $600 \mu$ pre-warmed, diluted blood into single-use test cells. These test cells contain 4 metal electrodes which are paired as two independent sensor units.

For statistical analysis the standard program SAS (Release 9.1) was used. The Chi-Square-test was used for the comparison of the three treatments in case of discontinuous variables. If SAS gave a warning that cells have expected counts less than 5 the test switched to the Likelihood ratio test. The continuous parameters were compared with the overall F-test of the GLM-procedure fol-lowed with the LSD-test as post-hoc-test. The test level is assumed with $\alpha=$ 0.05 .

\section{RESULTS}

Our results reveal a significant difference between the three groups concerning the bodyweight, the height, the BMI and the Euroscore (Table 1). The 4\% gelatin group was significantly taller and had a significantly higher body weight than the 6\% HES130/0.42 group. The Euroscore of the 6\% HES 130/0.42 group was significantly higher than the 6\% HES 200/0.5 group. For all other preoperative parameters there was no significant difference between the three groups (Table 1 and 2).

During surgery (phase 1) the $4 \%$ gelatin group and the $6 \%$ HES 200/0.5 group received significantly more aprotinine than the 6\% HES 130/0.42 group. The urinary excretion during phase 1 was significantly lower in the 6\% HES 130/0.42 group (Table 3). We saw no significant difference with regards to the administration of blood and coagulation products between the three groups.

On ICU (phase 2) the 4\% gelatin group received significantly more norepinephrine than the two other groups (Table 4). We saw no significant difference between the three groups with regards to the administration of other catecholamine's.

Furthermore we saw a significant decrease in platelet function in the $6 \%$ HES 200/0.5 group when performing the multiplate ${ }^{\circledR}$ analysis (ADP-and COL-test, Fig. 5 and 6). There was no significant decrease in the TRAP-test (Fig. 3). The 6\% HES $130 / 0.42$ group as well as well as the $4 \%$ gelatin 
Table 1. Demographic data, intraoperative and postoperative variables.

\begin{tabular}{lcccc}
\hline variables & $\begin{array}{c}\mathbf{6 \%} \mathbf{H E S ~ 1 3 0 / 0 . 4 2} \\
(\mathrm{n}=30)\end{array}$ & $\begin{array}{c}\mathbf{4 \%} \text { gelatin } \\
(\mathrm{n}=30)\end{array}$ & $\begin{array}{c}\mathbf{6 \%} \mathbf{H E S ~ 2 0 0 / 0 . 5} \\
(\mathrm{n}=30)\end{array}$ & p-value \\
\hline female $(\mathrm{n})$ & 12 & 5 & 12 & 0.0827 \\
age in years $\pm \mathrm{SD}$ & $69 \pm 13$ & $66 \pm 12$ & $67 \pm 10$ & $>0.2$ \\
body weight in $\mathrm{kg} \pm \mathrm{SD}$ & $72 \pm 15$ & $84 \pm 18$ & $75 \pm 12$ & $<0.05$ \\
body height in $\mathrm{cm} \pm \mathrm{SD}$ & $167 \pm 9$ & $173 \pm 8$ & $168 \pm 10$ & $<0.05$ \\
body mass index in $\mathrm{kg} / \mathrm{m}_{-} \pm \mathrm{SD}$ & $26 \pm 4$ & $28 \pm 6$ & $26 \pm 4$ & $<0.05$ \\
ejection fraktion in $\% \pm \mathrm{SD}$ & $59 \pm 15$ & $54 \pm 18$ & $63 \pm 15$ & $>0.2$ \\
euroscore $(\%) \pm \mathrm{SD}$ & $6 \pm 3$ & $4 \pm 2$ & $4 \pm 3$ & $<0.05$ \\
ASA Score (ASA 3), $\mathrm{n}$ & 25 & 23 & 24 & $>0.2$ \\
anamnestic coagulation disorder & 1 & 0 & 0 & $>0.2$
\end{tabular}

\section{aortocoronary bypass}

artery graft

one artery graft

two artery grafts

three artery grafts

venous graft

one venous graft

two venous grafts

three venous grafts

four venous grafts

valve replacement

mitral valve replacement

aortic valve replacement

valve reconstruction

mitral valve reconstruction

aortic valve reconstruction

$\begin{array}{cc}13 & 19 \\ 0 & 2 \\ 2 & 2\end{array}$

$\begin{array}{ccc} & & >0.2 \\ 19 & 17 & >0.2 \\ 2 & 2 & 0.2 \\ 2 & 1 & 0.2 \\ 1 & & 0.1835 \\ 11 & 3 & >2 \\ 7 & 10 & >0.2 \\ 0 & 4 & >0.2 \\ 1 & 1 & \\ 1 & & 0.2 \\ 6 & 0 & 0.1014 \\ & 10 & >0.2\end{array}$

temperature during $\mathrm{CPB}\left(30-35^{\circ} \mathrm{C}\right)$

cardiopegia ( St. Thomas)

duration of surgery ( $\min \pm S D)$

duration of $\mathrm{CPB}$ in $(\mathrm{min} \pm \mathrm{SD})$

$\begin{array}{cc}4 & 1 \\ 3 & 1 \\ 8 & 7 \\ 0 & 0 \\ 3 & 1 \\ 10 & 6\end{array}$

0.1835

aortic cross-clamp time ( $\min \pm S D)$

ICU-stay in days \pm SD

hospitalization in days $\pm \mathrm{SD}$

1
1

2
0

$1>0.2$

$0>0.2$

25

23

$198 \pm 59$

$104 \pm 37$

$59 \pm 24$

$1 \pm 1$

26

27

27
28

$>0.2$

$199 \pm 33$

28

0.0557

$178 \pm 36$

0.1214

$93 \pm 27$

$89 \pm 32$

0.196

$48 \pm 18$

$49 \pm 22$

0.1229

$12 \pm 6$

$2 \pm 5$

$1 \pm 1$

$>0.2$

$11 \pm 6$

$10 \pm 5$

$>0.2$

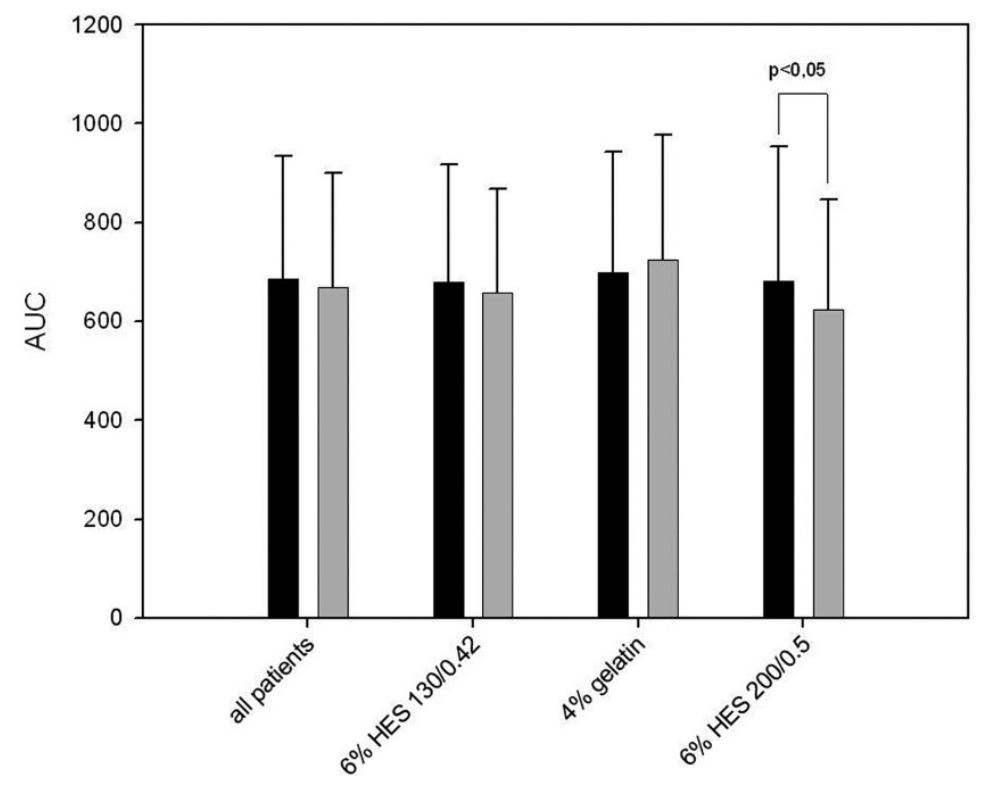

ADP before colloid administration ADP after colloid administration

Fig. 1. Multiplate ${ }^{\circledR}$ analysis: ADP-test. 
Table 2. Concomitant medication and concomitant diseases.

\begin{tabular}{|c|c|c|c|c|}
\hline variable & $\begin{array}{c}6 \% \text { HES } 130 / 0.42 \\
(\mathrm{n}=30)\end{array}$ & $\begin{array}{c}4 \% \text { gelatin } \\
(\mathrm{n}=30)\end{array}$ & $\begin{array}{c}6 \% \text { HES 200/0.5 } \\
(\mathrm{n}=30)\end{array}$ & p-value \\
\hline asperine & 15 & 17 & 19 & $>0.2$ \\
\hline NSAR & 0 & 3 & 1 & 0.1129 \\
\hline clopidogrel & 1 & 5 & 5 & 0.1351 \\
\hline phenprocoumon & 2 & 1 & 3 & $>0.2$ \\
\hline beta blocker & 19 & 19 & 19 & $>0.2$ \\
\hline calcium channel blocker & 6 & 3 & 3 & $>0.2$ \\
\hline ACE-inhibitors & 17 & 17 & 17 & $>0.2$ \\
\hline diuretic & 14 & 16 & 13 & $>0.2$ \\
\hline digoxin & 3 & 4 & 2 & $>0.2$ \\
\hline statine drug & 14 & 17 & 17 & $>0.2$ \\
\hline nitrate & 8 & 5 & 7 & $>0.2$ \\
\hline arterial hypertension & 21 & 18 & 20 & $>0.2$ \\
\hline pulmonary hypertension & 3 & 3 & 1 & $>0.2$ \\
\hline diabetes mellitus & 4 & 8 & 8 & $>0.2$ \\
\hline smoker & 4 & 10 & 10 & 0.1176 \\
\hline hypercholesteremia & 11 & 11 & 15 & $>0.2$ \\
\hline adiposity & 7 & 12 & 10 & $>0.2$ \\
\hline coronary artery disease & 20 & 21 & 26 & 0.1636 \\
\hline familial heart diseases & 1 & 3 & 6 & 0.1166 \\
\hline left main (coronary artery) stenosis & 6 & 9 & 11 & $>0.2$ \\
\hline multi-vessel coronary disease & 16 & 20 & 19 & $>0.2$ \\
\hline myocardial infarction & 2 & 7 & 8 & 0.1192 \\
\hline atrial fibrillation & 4 & 4 & 3 & $>0.2$ \\
\hline ischemic cardiomyopathy & 2 & 2 & 0 & 0.1886 \\
\hline mitral valve insufficiency & 9 & 7 & 6 & $>0.2$ \\
\hline aortic valve insufficiency & 8 & 4 & 4 & $>0.2$ \\
\hline aortic valve stenosis & 10 & 4 & 10 & 0.1293 \\
\hline COPD & 7 & 10 & 4 & 0.1869 \\
\hline
\end{tabular}

Table 3. Crystalloids, blood components, urinary excretion, coagulation products and catecholamine from the anesthetic induction till the end of surgery (phase 1).

\begin{tabular}{|c|c|c|c|c|}
\hline variable & $\begin{array}{c}\text { 6\% HES 130/0.42 } \\
(\mathrm{n}=30)\end{array}$ & $\begin{array}{l}4 \% \text { gelatin } \\
(\mathrm{n}=30)\end{array}$ & $\begin{array}{c}\text { 6\% HES 200 } \\
(\mathrm{n}=30)\end{array}$ & p-value \\
\hline saline $(\mathrm{ml}) \pm \mathrm{SD}$ & $2008 \pm 476$ & $2028 \pm 799$ & $2007 \pm 357$ & $>0.2$ \\
\hline other crystalloides $(\mathrm{ml}) \pm \mathrm{SD}$ & $1318 \pm 265$ & $1289 \pm 326$ & $1231 \pm 423$ & $>0.2$ \\
\hline red cell concentrate $(\mathrm{n}) \pm \mathrm{SD}$ & $3 \pm 1$ & $3 \pm 2$ & $3 \pm 1$ & $>0.2$ \\
\hline fresh frozen plasma (n) \pm SD & $4 \pm 1$ & $3 \pm 1$ & $3 \pm 1$ & $>0.2$ \\
\hline platelet concentrate (n) \pm SD & $2 \pm 1$ & $2 \pm 1$ & $2 \pm 0.0$ & $>0.2$ \\
\hline bicarbonate $8.4 \%(\mathrm{ml}) \pm \mathrm{SD}$ & $46 \pm 21$ & $48 \pm 31$ & $47 \pm 22$ & $>0.2$ \\
\hline urinary excretion $(\mathrm{ml}) \pm \mathrm{SD}$ & $421 \pm 245$ & $570 \pm 356$ & $690 \pm 468$ & $<0.05$ \\
\hline aprotinine $(\mathrm{mE}) \pm \mathrm{SD}$ & $1 \pm 1$ & $2 \pm 1$ & $2 \pm 1$ & $<0.05$ \\
\hline heparine (IE) \pm SD & $37250 \pm 8914$ & $38167 \pm 7484$ & $37833 \pm 6914$ & $>0.2$ \\
\hline protamine ( IE) $\pm \mathrm{SD}$ & $34500 \pm 6991$ & $37500 \pm 7399$ & $36167 \pm 6783$ & $>0.2$ \\
\hline norepinephrine $(\mathrm{mg}) \pm \mathrm{SD}$ & $1 \pm 1$ & $1 \pm 1$ & $2 \pm 1$ & 0.1275 \\
\hline dobutamine $(\mathrm{mg}) \pm \mathrm{SD}$ & $26 \pm 10$ & $28 \pm 20$ & $25 \pm 6$ & $>0.2$ \\
\hline
\end{tabular}

group showed no significant change in platelet function. These data are supported by the evaluation of the responsible surgeon who considered the blood coagulation in the $6 \%$ HES $200 / 0.5$ group most frequently impaired.

\section{Discussion}

Hyovolemia is widespread among patients in cardiac surgery and an adequate fluid resuscitation is essential for the outcome of these patients. A change in demo- 
Table 4. Crystalloids, blood components, urinary excretion, coagulation products and catecholamine from the end of surgery till 24 hours stay on the ICU (phase 2).

\begin{tabular}{|c|c|c|c|c|}
\hline variable & $\begin{array}{c}6 \% \text { HES } 130 / 0.42 \\
(n=30)\end{array}$ & $\begin{array}{c}4 \% \text { gelatin } \\
(\mathrm{n}=30)\end{array}$ & $\begin{array}{c}\text { 6\% HES 200/0.5 } \\
(\mathrm{n}=30)\end{array}$ & p-value \\
\hline saline $(\mathrm{ml}) \pm \mathrm{SD}$ & $3173 \pm 1428$ & $3265 \pm 1410$ & $3169 \pm 1218$ & $>0.2$ \\
\hline other crystalloides $(\mathrm{ml}) \pm \mathrm{SD}$ & $1318 \pm 265$ & $1289 \pm 326$ & $1231 \pm 424$ & $>0.2$ \\
\hline red cell concentrate $(n) \pm S D$ & $4 \pm 2$ & $4 \pm 2$ & $4 \pm 2$ & $>0.2$ \\
\hline fresh frozen plasma (n) \pm SD & $4 \pm 1$ & $4 \pm 2$ & $4 \pm 1$ & $>0.2$ \\
\hline platelet concentrate (n) \pm SD & $2 \pm 1$ & $2 \pm 1$ & $2 \pm 1$ & $>0.2$ \\
\hline bicarbonate $8.4 \%(\mathrm{ml}) \pm \mathrm{SD}$ & $46 \pm 21$ & $48 \pm 31$ & $47 \pm 22$ & $>0.2$ \\
\hline urinary excretion $(\mathrm{ml}) \pm S D$ & $2993 \pm 1376$ & $3251 \pm 1210$ & $3446 \pm 882$ & $>0.2$ \\
\hline aprotinine $(\mathrm{mE}) \pm \mathrm{SD}$ & $2 \pm 1$ & $2 \pm 1$ & $2 \pm 1$ & 0.1888 \\
\hline heparine (IE) \pm SD & $119200 \pm 81597$ & $98667 \pm 78300$ & $87667 \pm 73693$ & $>0.2$ \\
\hline protamine ( IE) $\pm S D$ & $34500 \pm 6991$ & $37500 \pm 7399$ & $36167 \pm 6783$ & $>0.2$ \\
\hline norepinephrine $(\mathrm{mg}) \pm \mathrm{SD}$ & $2 \pm 3$ & $9 \pm 9$ & $8 \pm 6$ & $<0.05$ \\
\hline dobutamine $(\mathrm{mg}) \pm \mathrm{SD}$ & $177 \pm 76$ & $276 \pm 150$ & $197 \pm 123$ & 0.1181 \\
\hline
\end{tabular}

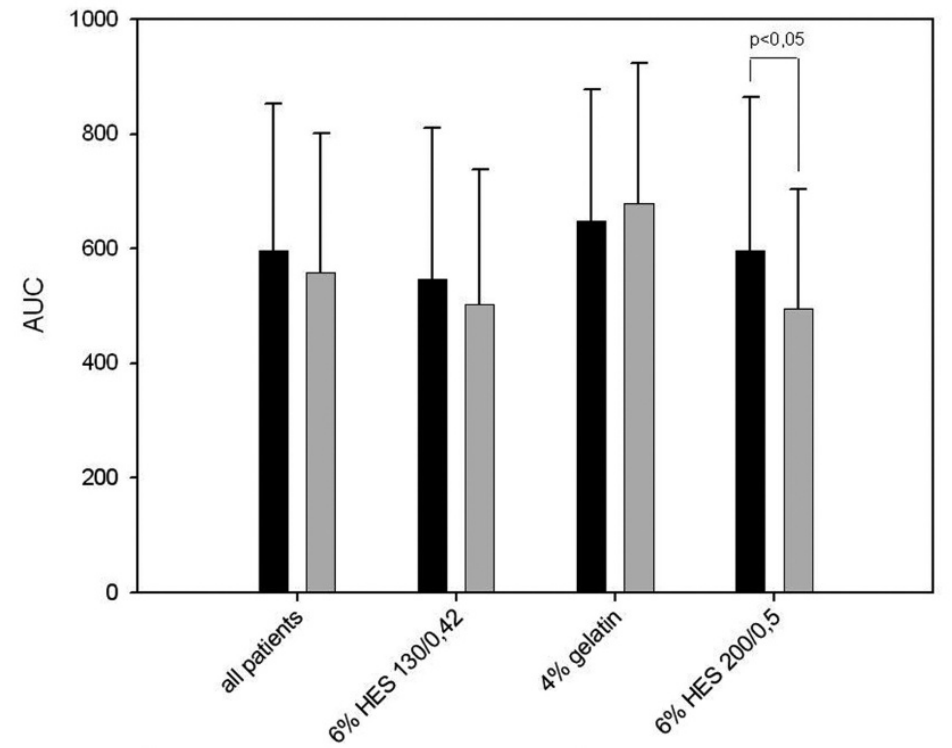

COL before colloid administration $\mathrm{COL}$ after colloid administration

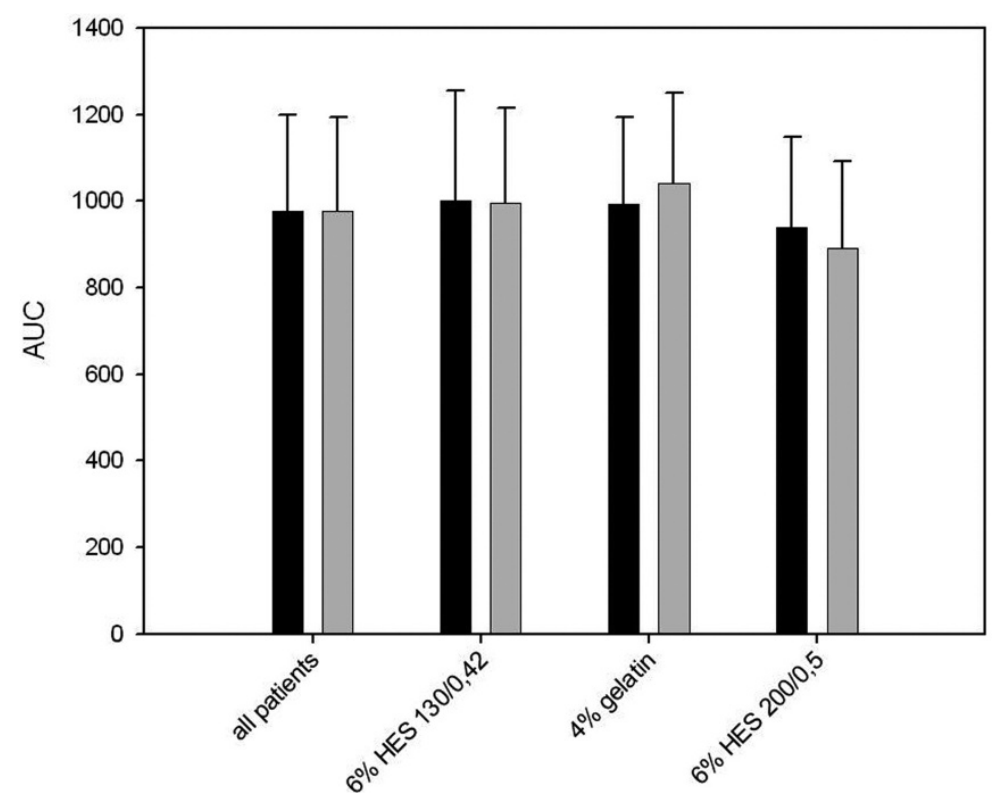

Fig. 2. Multiplate ${ }^{\circledR}$ analysis: COL-test.

TRAP before colloid administration TRAP after colloid administration 
graphics in Germany has lead to a significant increase in the mean age of patients undergoing an open-heart surgery resulting in higher mortality rates and an increased rate of postoperative complications [13, 14]. These complications comprise a protracted ICU-stay, the frequent application of blood products and a renal dysfunction.

Hence a permanent verification of the colloids used for treating hypovolemia is mandatory for an early detection of adverse events and thereby reducing or even avoiding these complications in this challenging patient population.

The objective of these study was to compare 3 frequently used colloids with regards to their safety in clinical use in cardiac surgery. Consequently we focused mainly on the influence on the renal function and the alteration of the blood coagulation as being frequently described side effects of these preparations. Furthermore the comparison of the influence of hemodynamics and the volume effect of the three colloids was a major objective of these studies.

Acute renal failure is a serious complication following cardiac surgery and a permanent reduction in renal function will exhibit independent effects on patient survival that extends well beyond discharge from the hospital $[15,16]$. There was no difference regarding creatinine and urea concentration between the three groups. Furthermore we saw no difference concerning the administration of diuretics. But our results show a significantly lower urinary excretion in the 6\% HES 130/0.42 group during surgery (phase 1). This result surprised since the third generation of HES preparations (130/ $0.4)$ is supposed to be associated with fewer changes in kidney function than the former HES generations.

Even after the application of a very high dosage of $6 \%$ HES 130/0.4 in patients undergoing neurosurgical intervention there was no deteriorating kidney function seen [17].

Boldt et al. showed in a study with cardiac patients over the age of 80 that the use of HES 130/0.4 was associated with fewer changes in kidney function than after the use of gelatin [18]. Possible reasons for the significantly lower urinary excretion in the 6\% HES $130 / 0.42$ group might be an influence of the additional administration of crystalloids during the surgical intervention and the higher Euroscore of the $6 \%$ HES $130 / 0.42$ group.

Our results show that the $4 \%$ gelatin group needed significantly more norepinephrine than the two other groups during the ICU-stay (phase 2). Hence the volume effect of gelatin can be considered as being lower than the two HES preparations. These results are being confirmed by Boldt et al. who needed significantly more gelatin than a "third" generation HES preparation to obtain an equal volume effect [18]. Other authors saw an equal volume effect of HES preparations and gelatin preparations [19-22]. A limitation of our studies is certainly the significantly higher body weight of the gelatin group. As mentioned we administrated each patient regardless to their body weight $500 \mathrm{ml}$ of the respective colloid as part of the anesthetic induction resulting in a lower dosage per kilogram body weight. This may have contributed to the lower volume effect seen in the gelatin group.
We analyzed several data for evaluating the influence of the colloids on the blood coagulation and platelet function. Aprotinin was effectively used for reducing intra-and postoperative blood drainage and transfusion requirements and thus its administration can be used as a marker for evaluating the blood coagulation [23]. We found a significantly higher aprotinin administration during surgery in the gelatin group compared to the other groups. The 6\% HES 200/0.5 group received significantly more aprotinin than the to the 6\% HES 130/0.4 group. Furthermore the responsible surgeon considered the blood coagulation in the HES 200/0.5 group most frequently impaired.

Interestingly these subjective parameters evaluating blood coagulation were confirmed by the objective measurement of platelet aggregation using multiplate electrode analyzer. We saw a significant decrease in aggregation after the administration of $6 \%$ HES 200/0.5 in the ADP-test as well as in the COL-test. These tests perform submaximal stimulation of platelet aggregation. In contrast, in the TRAP-test we saw no significant change in aggregation. This test performs a maximal stimulation of platelet aggregation being a possible explanation for our results. Interestingly we saw no difference using multiplate electrode analyzer regarding the $4 \%$ gelatin group and the $6 \%$ HES 130/0.4 group.

Our results are confirmed by several studies showing an advantage of the 3rd generation of HES preparation over the 2 nd generation with regard to blood coagulation and platelet function [9, 24-26].

There are several limitations that have to be considered when interpreting our results. The $4 \%$ gelatin group was significantly taller and had a significantly higher body weight than the 6\% HES130/0.42 group. Furthermore the Euroscore of the 6\% HES 130/0.42 group was significantly higher than the 6\% HES 200/0.5 group. To allow an exact comparison between the three groups all patients should have received the similar dosage of the colloid per kilogram bodyweight. But this is only accomplishable in an prospective randomized study and not in an obervational study.

In summary, we have shown that gelatin has a lower stabilizing effect on circulation during fluid resuscitation. The blood coagulation was mostly impaired due to HES 200/0.5 confirmed by the multiplate ${ }^{\circledR}$-analysis as well as by different clinical findings.

Conflict of interest: no

\section{REFERENCES}

1. Knotzer H, Maier S, Dünser MW, Ulmer H, Schwarz B, et al. Comparison of lactated Ringer's, gelatine and blood resuscitation on intestinal oxygen supply and mucosal oxygen tension in haemorrhagic shock. Br J AnaesthBr J Anaesth. 2006; 97: 509-516.

2. Hillman K, Bristow P. The crystalloid versus colloid controvery: present status. Balliere`s Clin Anaesth. 1997; 11:1-13.

3. Otsuki DA, Margarido CB, Marumo CK, Intelizano T, Pasqualucci CA, et al. Hydroxyethyl starch is superior to Ringer as a replacement fluid in a pig model of acute normovolaemic haemodilution. Br J Anasth. 2007; 98: 29-37.

4. Boldt J, Andinet A. New Plasma-Adapted Hydroxyethylstarch Preparation: In vitro Coagulation Studies Using Thrombelastography and Whole Blood Aggregometry. Anesth Analg. 2007; 104: 425-430. 
5. Langeron $\mathrm{O}$, Ang E-T, Bonnet F, Capdevila X, Coriat P. Voluven ${ }^{\circledR}$, a Lower Substituted Novel Hydroxyethyl Starch (HES 130/0.4), Causes Fewer Effects on Coagulation in Major Orthopedic Surgery than HES 200/0.5. Anesth Analg. 2001; 92: 855-862.

6. Treib J, Grauer MT, Strauss RG. An international view of hydroxyethyl starches. Intensive Care Med. 1999; 25: 258268.

7. Laxenaire MC, Feldman L. Reactions anaphylactoides aux substituts colloideaux du plasma: incidence, facteurs de risque, me'canismes. Ann Fr Anesth Re'anim. 1994; 13: 301-310.

8. Boldt J. Modern Rapidly Degradable Hydroxyethyl Starches:Current Concepts. Anesth Analg, 2009; 108: 1574-1582.

9. Gallandat H, Baus D et al. A novel hydroxyethyl starch $\left(\right.$ Voluven $^{\circledR}$ ) for effective perioperative plasma volume substitution in cardiac surgery. Can J Anesth. 2000; 47: 1207-1215.

10. Günther Haisch JB, Krebs C, Suttner S. Influence of a New Hydroxyethylstarch Preparation (HES 130/0.4) on Coagulation in Cardiac Surgical Patients. J Cardiothor Vasc Anesthesia. 2001; 15: 316-321.

11. Kasper SM, Kampe S, Görg C, Geisen C, Mehlhorn U, Diefenbach C. Large-dose hydroxyethyl starch 130/0.4 does not increase blood loss and transfusion requirements in coronary artery bypass surgery compared with hydroxyethyl starch $200 / 0.5$ at recommended doses. Anesthesiology. 2003; 99: 42-7.

12. Scharbert G, Marschalek C, Kozek-Langenecker SA. The Effects of Test Temperature and Storage Temperature on Platelet Aggregation: A Whole Blood In vitro Study. Anesth Analg. 2006; 102: 1280-4.

13. Bruckenberger E. Herzbericht 2007. 2007 [cited 02.08. 2009]; Available from: http://www.bruckenberger.de.

14. Friedrich I, Kötting J, Thölen F, Fischer B Silber R-E. Cardiac Surgery in the Elderly Patient. Dtsch Arztebl Int. 2009; 106: 412-422.

15. Schiffl $\mathrm{H}$. Renal recovery after severe acute renal injury. Eur J Med Res. 2008; 13: 552-556.

16. Wiebe K, Wahlers T, Zenker D, Schulze F, Michels P, Dalichau H, Mohr FW, Borst H, Forssmann WG. Acute renal failure following cardiac surgery is reverted by administration of Urodilatin (INN: Ularitide). Eur J Med Res. 1996; 1: 259-265.

17. Neff TA, Jungheinrich C, Sauerland A, Spahn DR, Stocker R. Repetitive large-dose infusion of the novel hydroxyethyl starch $130 / 0.4$ in patients with severe head injury. Anesth Analg. 2003; 96: 1453-1459.

18. Boldt J, Röhm K, Papsdorf M, Mengistu A. Comparison of the effects of gelatin and a modern hydroxyethyl starch solution on renal function and inflammatory response in elderly cardiac surgery patients. Brit J Anaesthesia. 2008; 100: 457-464.
19. Innerhofer P, Margreiter J, Klingler A, Kühbacher G, Wachter B, et al. The effects of perioperatively administered colloids and crystalloids on primary platelet-mediated hemostasis and clot formation. Anesth Analg. 2002; 95: 858-865.

20. Van der Linden PJ, Daper A, Trenchant A, Schmartz D, Defrance P, et al. 3,5\% urea-linked gelatine is as effective as $6 \%$ HES $200 / 0.5$ for volume management in cardiac surgery patients. Can J Anesth. 2004; 51: 236-241.

21. Van der Linden PJ, Deraedt D, Cromheecke S, De Decker K, De Paep R, et al. Hydroxyethyl starch 130/0.4 versus modified fluid gelatine for volume expansion in cardiac surgery patients: The effects on perioperative bleeding and transfusion needs. Anesth Analg. 2005; 101: 629634.

22. Haisch G, Krebs C, Kumle B, Suttner S, Schulz A. The influence of intravascular volume therapy with a new hydroxyethyl starch preparation $(6 \%$ HES $130 / 0,4)$ on coagulation in patients undergoing major abdominal surgery. Anesth Analg. 2001; 92: 565-570.

23. Khalil PN, Ismail M, Khalil MN, von Knobelsdorff G, Marx G, Kalmar P. The critical role of aprotinin in controlling haemostasis in conjunction with non-pharmacological blood-saving strategies during routine coronary artery bypass surgery. Eur J Med Res. 2006; 11: 386-393.

24. Franz A, Gamsjäger T, Felfernig M, Gustorff B, KozekLangenecker SA., The effects of hydroxyethyl starches of varying molecular weights on platelet function. Anesth Analg, 2001. 92: 1402-1407.

25. Konrad CJ, Markl TJ, Schuepfer GK, Schmeck J, Gerber HR. In-Vitro effects of different medium molecular hydroxyethyl starch solutions and lactated Ringer's solution on coagulation using Sonoclot. Anesth Analg. 2000; 90: 274-9.

26. Felfernig M, Bräunlich P, Fohringer C, Kozek-Langenecker SA. The effects of hydroxyethyl starch solutions on thromboelastography in preoperative male patients. Acta Anaesthesiol Scand. 2003; 47: 70-73.

Received: December 30, 2009 / Accepted: June 18, 2010

Address for correspondence:

Michael Winterhalter M.D.

University of Düsseldorf

Dept. of Anaesthesiology

Moorenstr.5

40225 Düsseldorf

Germany

Tel.: +49-21181-17828

E-mail: Michael.Winterhalter@med.uni-duesseldorf.de 